Spring 2018

\title{
Clinical Applications of the Pipeline Embolization Device
}

\author{
Badih Daou, MD \\ Thomas Jefferson University \\ Elias Atallah, MD \\ Thomas Jefferson University \\ Evan Fitchett, BS \\ Thomas Jefferson University \\ Nohra Chalouhi, MD \\ Thomas Jefferson University \\ Robert Starke, MD \\ Thomas Jefferson University
}

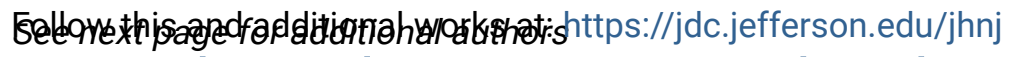 Let us know how access to this document benefits you}

\section{Recommended Citation}

Daou, MD, Badih; Atallah, MD, Elias; Fitchett, BS, Evan; Chalouhi, MD, Nohra; Starke, MD, Robert; Oliver, BS, Jeffrey; Montano, BS, Maria; Jabbour, Pascal MD; Rosenwasser, MD, MBA, FACS, FAHA, Robert H.; and Tjoumakaris, MD, FAANS, Stavropoula (2018) "Clinical Applications of the Pipeline Embolization Device," JHN Journal: Vol. 13 : Iss. 2 , Article 4.

DOI: https://doi.org/10.29046/JHNJ.013.2.004

Available at: https://jdc.jefferson.edu/jhnj/vol13/iss2/4

This Article is brought to you for free and open access by the Jefferson Digital Commons. The Jefferson Digital Commons is a service of Thomas Jefferson University's Center for Teaching and Learning (CTL). The Commons is a showcase for Jefferson books and journals, peer-reviewed scholarly publications, unique historical collections from the University archives, and teaching tools. The Jefferson Digital Commons allows researchers and interested readers anywhere in the world to learn about and keep up to date with Jefferson scholarship. This article has been accepted for inclusion in JHN Journal by an authorized administrator of the Jefferson Digital Commons. For more information, please contact: JeffersonDigitalCommons@jefferson.edu. 


\section{Clinical Applications of the Pipeline Embolization Device}

\section{Authors}

Badih Daou, MD; Elias Atallah, MD; Evan Fitchett, BS; Nohra Chalouhi, MD; Robert Starke, MD; Jeffrey

Oliver, BS; Maria Montano, BS; Pascal Jabbour MD; Robert H. Rosenwasser, MD, MBA, FACS, FAHA; and Stavropoula Tjoumakaris, MD, FAANS 


\section{Clinical Applications of the Pipeline Embolization Device}

\author{
Badih Daou, MD*; Elias Atallah, MD*; Evan Fitchett, BS; Chalouhi Nohra, MD; \\ Robert Starke MD; Jeffrey Oliver, BS; Maria Montano, BS; Pascal Jabbour, MD; \\ Robert H. Rosennwasser, MD, MBA, FACS, FAHA; Stavropoula Tjoumakaris, MD, \\ FAANS \\ Department of Neurological Surgery, Thomas Jefferson University and Jefferson Hospital \\ for Neuroscience, Philadelphia, PA \\ *Authorship Note: Badih Daou and Elias Atallah contributed equally to this work as co-first authors
}

Flow diverters (FDs) are being used with increasing frequency, especially to target large and complex aneurysms not amenable to treatment with conventional endovascular methods. ${ }^{8,10,11,26}$ The Pipeline embolization device (PED) is the first FD approved by the FDA following the results of the PUFS trial for the management of large or giant wide-necked intracranial aneurysms in the internal carotid artery from the petrous to the superior hypophyseal segments. Although initially indicated for a limited type of aneurysms, the use of the PED is being extended for the management of a variety of aneurysms in different settings. ${ }^{5-7,9}$ The main factors that are considered in deciding if an aneurysm is suitable for treatment with the PED include aneurysm size, location, geometry and shape and rupture status. ${ }^{16}$ Studies have shown a high technical success rate, a high rate of aneurysm occlusion accompanied by low recurrence and re-treatment rates. ${ }^{10,12,20}$ Current evidence also supports the PED as a safe device associated with low morbidity and mortality. 10,21,23,27 Although treatment failure with flow diversion has been reported, the characteristics of these aneurysms with persistent filling have not been well established. Furthermore, the course of these aneurysms remains a topic of uncertainty. The initial thrombosis caused by FDs does not result in immediate cure of the aneurysm rather FDs act as a scaffold for endothelial overgrowth at the aneurysm neck resulting intra-aneurysmal flow stasis and thrombosis while promoting remodeling of the parent vessel and parent vessel reconstruction which results in gradual occlusion of the aneurysm. ${ }^{22}$

Prior literature on the efficacy of PED have shown a high complete aneurysm occlusion rate, with most studies reporting occlusion rates $>80 \% 3,13$ and this compares favorably to endovascular coil embolization, where the reported complete occlusion rate is $66 \%$ (ISAT). ${ }^{4}$ Recurrence after successful PED treatment has not been reported with the available short- and medium-term data. This is in contrast to high recurrence rates with coiling (9-34\% at 12 months) that increases with large, giant, wide-necked, and nonsaccular aneurysms that are the target for PED treatment. ${ }^{1}$ The retreatment rate is much lower with PED treatment as compared to coiling in ISAT (17.4\%). ${ }^{4}$ Flow diverters seem to be more effective than the conventional endovascular techniques in select cases.

Aneurysm location in the distal anterior circulation (PCOM artery, anterior choroidal artery and MCA) is a significant predictor of persistent aneurysm. Parent vessels for such aneurysms are usually small, and aneurysms often arise at major branch points. In addition, the A1 segment of the ACA and M1 segment of the MCA are rich in lenticulo-striate perforators, and covering these areas with PEDs could theoretically increase the risk of perforator strokes with neurological deficits. These factors render PED delivery and deployment more difficult. Also, PEDs (with available sizes from 2.5 to $5 \mathrm{~mm}$ ) are in general designed for parent vessels that are larger than the caliber of distal anterior circulation vessels. In a small vessel, the device may be elongated and the stent pores may become larger which may impair the flow diversion effect and lower the chances of aneurysm thrombosis. This may affect the reliability of PED deployment in smaller distal vessels. However, there are some distal anterior circulation aneurysms that are morphologically challenging for either traditional microsurgical or endovascular approaches, and the use of PEDs may have an advantage in these cases. In these cases, placing a single, long flow diverter stent and avoiding telescoping of multiple devices along perforator-rich segments can reduce the risk of perforator occlusion.

The PED was originally approved for the treatment of aneurysms proximal to the PCOM artery. ${ }^{14}$ PCOMA aneurysms are among the most frequently encountered cerebral aneurysms. A fetal PCOM artery is an end vessel with no distal collaterals. Since fetal PCOM arteries represent the only supply to the PCA, care should be taken when treating PCOM aneurysms incorporating a fetal variant. ${ }^{19}$ In fact, fetal PCOM artery aneurysms are often treated surgically since endovascular therapy is thought to cause a higher treatment risk. ${ }^{19}$ Several reports have suggested that flow diversion for fetal PCOM aneurysms is ineffective and does not lead to aneurysm occlusion and has high potential for serious complications. ${ }^{17,19}$ Aneurysms arising from a fetal PCOM are less likely to be occluded even after placement of a flow diverter due to the high flow and the high physiological demand for this artery which maintains pressure gradient across the ostium. ${ }^{14}$ PCOM aneurysms with a fetal PCA are better to be treated with microsurgical clipping. ${ }^{18}$ Attempting flow diversion may add procedural risks and make surgical clipping even more technically complex.

MCA aneurysms represent the third most common cause of subarachnoid hemorrhage and almost $1 / 5$ of unruptured aneurysms. ${ }^{24}$ The majority of MCA aneurysms arise at the level of the bifurcation tend to be wide-necked, incorporate one 
or more side branch vessels and tend to have an unfavorable anatomical configuration. ${ }^{15}$ Wide-necked MCA bifurcation lesions have been classically treated with microsurgery with excellent results. Traditional endovascular approaches can sometimes be challenging with a risk of occluding branch vessels as well as the risk of coil herniation. Flow diversion for MCA aneurysms should be considered when other surgical or endovascular approaches are not an option or do not offer superior outcomes and for lesions that persist after previous surgery or endovascular treatment. ${ }^{26}$ Clinical data should demonstrate better or similar results than clipping to challenge surgical intervention, with current occlusion rates from clipping reported to be $>90 \%$ in most studies. ${ }^{25}$

Stent placement negatively affects the safety and efficacy of the PED in the management of recurrent aneurysms. The rate of complete aneurysm occlusion is lower in previously stented aneurysms (50-65\%) with potential for a higher complication rate $(14.3 \%)$ and technical failure rate. ${ }^{28}$ If a stent was placed initially, recurrence would be less eligible for PED treatment and might require surgical clipping to achieve aneurysm occlusion. The presence of a previous stent may: reduce the hemodynamic effect of the PED, disrupt the process of wall apposition of the PED to the parent vessel, preventing the endothelialization process inhibiting complete aneurysm occlusion, complicate the navigation of the delivery catheter into position and the actual deployment of the PED and because the PED should be deployed distal to the stent, the distal end of the PED may "catch" on the previously placed stent, which may cause anchoring and stretching of the device, leading to less effective results. It is important to note that patients of advanced age can have a weaker neo-intimal response and therefore may have higher odds of incomplete aneurysm occlusion.

The majority of cases require the placement of only one PED, and a single PED should be usually placed as there was no difference in aneurysm occlusion when more than 1 device were deployed. ${ }^{29}$ Coiling and flow diversion have been shown to be complementary, rather than competitive modalities for intracranial aneurysm treatment. ${ }^{3}$ Using coils along with the PED in select cases can be more effective with a higher occlusion rate and lower retreatment rate, by promoting endosaccular thrombosis and providing a mechanical scaffold.

The PED is indicated for large and giant aneurysms. ${ }^{4}$ However, large and giant aneurysms represent a small fraction of all cerebral aneurysms with the majority of aneurysms in the general population being $<10 \mathrm{~mm}$ in size. Traditional endovascular strategies including coiling and stent-assisted coiling are usually used for small aneurysms ( $\leq 7 \mathrm{~mm})$. Some retrospective studies have demonstrated high occlusion rates (75-90\%) and low complication rates $(<5 \%)$ with treating these small aneurysms. ${ }^{10}$ In experienced centers the PED is demonstrating a better efficacy profile and a similar safety profile to coiling of smaller aneurysms. ${ }^{10}$ With the increasing use of the PED for the treatment of small, simple aneurysms, the question arises as to whether the use of this device routinely, or even as a first line treatment for these aneurysms is as safe and effective as the current standard endovascular techniques. This needs to be further studied

Good clinical outcomes have been reported with flow diversion of saccular or non-symptomatic fusiform posterior circulation aneurysms. ${ }^{3}$ Treatment with the PED may be a preferable alternative to open surgical treatment for these aneurysms. Because of the large number of perforating vessels in the posterior circulation that supply vital brainstem structures, complex aneurysm anatomy, and aneurysm location, flow diversion should be used with caution. Aneurysm morphology and presentation are critical factors to consider when selecting posterior circulation aneurysms for treatment with the PED. ${ }^{30}$

Device deployment is successful in $95 \%$ to $100 \%$ of cases ( $99 \%$ in PUFS). ${ }^{2}$ Selection of the appropriate diameter and length of the device is essential to ensure proper device function and to minimize the chance for unanticipated stent shortening or migration. (FDA-Summary of Safety and Effectiveness of Data, $P E D, P 100018)$ The delivery catheter must recross the PED over the delivery wire to recapture the distal coil tip after complete stent deployment. Up to 50\% foreshortening is expected when fully deployed compared with $1.5 \%-7.1 \%$ and $1.8 \%-5.4 \%$ foreshortening in Wingspan ${ }^{\circledR}$ and Neuroform ${ }^{\circledR} 3$ stents. (Bench testing conducted by Boston Scientific)

There is a potential risk of an endoleaklike phenomenon with implantation of an undersized device, which results in poor wall apposition. Similarly, implantation of an oversized device may result in poor coverage of the lesion because of an incomplete compaction of the strands. ${ }^{31}$ When a branch vessel is incorporated into the target aneurysm, its runoff can potentially contribute to persistent filling of the aneurysm by the very same physiological processes theoretically responsible for the preservation of jailed branch vessels and perforators arising from normal segments. One may expect that final closure of such aneurysms would require concomitant occlusion of the associated branch.

While the PED can allow for treatment of large, wide-necked aneurysms with high efficacy, aneurysm location, previous treatment, patient age and the use of concomitant coiling may influence treatment outcomes.

\section{REFERENCES}

1. Adriana Campi NR, Andrew J. Molyneux, Paul E. Summers, Richard S.C. Kerr, Mary Sneade, Julia A. Yarnold, Joan Rischmiller and James V. Byrne: eatment of Ruptured Cerebral Aneurysms in Patients Randomized by Coiling or Clipping in the International Subarachnoid Aneurysm Trial (ISAT). Stroke 38:1538-1544, 2007

2. Becske T, Kallmes DF, Saatci I, McDougall CG, Szikora I, Lanzino G, et al: Pipeline for uncoilable or failed aneurysms: results from a multicenter clinical trial. Radiology 267:858868,2013

3. Byung Moon Kim M, Yong Sam Shin, MD, Min Woo Baik, MD, Deok Hee Lee, MD, Pyoung Jeon et al. : Pipeline Embolization Device for Large/Giant or Fusiform Aneurysms: An Initial Multi-Center Experience in Korea. Neurointervention 11:10-17, 2016

4. Carmelo L. Sturiale WB, Mohammad H. Murad and Giuseppe Lanzino: Endovascular treatment of intracranial aneurysms in elderly patients: a systematic review and meta-analysis. Stroke 44:1897-1902, 2013 
5. Chalouhi N, Jabbour P, Gonzalez LF, Dumont AS, Rosenwasser R, Starke RM, et al: Safety and efficacy of endovascular treatment of basilar tip aneurysms by coiling with and without stent assistance: a review of 235 cases. Neurosurgery 71:785-794, 2012

6. Chalouhi N, Penn DL, Tjoumakaris S, Jabbour P, Gonzalez LF, Starke RM, et al: Treatment of small ruptured intracranial aneurysms: comparison of surgical and endovascular options. J Am Heart Assoc 1:e002865, 2012

7. Chalouhi N, Starke RM, Koltz MT, Jabbour PM, Tjoumakaris SI, Dumont AS, et al: Stentassisted coiling versus balloon remodeling of wide-neck aneurysms: comparison of angiographic outcomes. AJNR Am J Neuroradiol 34:1987-1992, 2013

8. Chalouhi N, Tjoumakaris S, Phillips JL, Starke RM, Hasan D, Wu C, et al: A single pipeline embolization device is sufficient for treatment of intracranial aneurysms. AJNR Am J Neuroradiol 35:1562-1566, 2014

9. Chalouhi N, Tjoumakaris S, Starke RM, Gonzalez LF, Randazzo C, Hasan D, et al: Comparison of flow diversion and coiling in large unruptured intracranial saccular aneurysms. Stroke 44:2150-2154, 2013

10. Chalouhi N, Zanaty M, Whiting A, Yang S, Tjoumakaris S, Hasan D, et al: Safety and efficacy of the Pipeline Embolization Device in 100 small intracranial aneurysms. J Neurosurg 122:1498-1502, 2015

11. Chan RSK, Mak CHK, Wong AKS, Chan KY, Leung KM: Use of the Pipeline Embolization Device to Treat Recently Ruptured Dissecting Cerebral Aneurysms. Interventional Neuroradiology 20:0, 2014

12. D'Urso PI, Lanzino G, Cloft HJ, Kallmes DF: Flow diversion for intracranial aneurysms: a review. Stroke 42:2363-2368, 2011

13. Giacomini L, Piske RL, Baccin CE, Barroso M, Joaquim AF, Tedeschi H: Neurovascular reconstruction with flow diverter stents for the treatment of 87 intracranial aneurysms: Clinical results. Interv Neuroradiol 21:292299, 2015
14. Golshani K, Ferrell A, Zomorodi A, Smith TP, Britz GW: A review of the management of posterior communicating artery aneurysms in the modern era. Surg Neurol Int 1:88, 2010

15. Islak C, Kizilkilic O, Kocak B, Saglam M, Yildiz $\mathrm{B}$, Kocer N: Use of buddy wire to facilitate Y-configured stent placement in middle cerebral artery bifurcation aneurysms with daughter branches arising from the sac: a technical note. Neurosurgery $10 \mathrm{Suppl}$ 1:E167-171; discussion E171, 2014

16. Jabbour P, Chalouhi N, Tjoumakaris $S$, Gonzalez LF, Dumont AS, Randazzo C, et al: The Pipeline Embolization Device: learning curve and predictors of complications and aneurysm obliteration. Neurosurgery 73:113120; discussion 120, 2013

17. Kan P1 DE, Puri A2, Velat G1, Wakhloo A2 Treatment failure of fetal posterior communicating artery aneurysms with the pipeline embolization device. Neurointerventional Surgery, 2016

18. Kuzmik GA, Bulsara KR: Microsurgical clipping of true posterior communicating artery aneurysms. Acta Neurochir (Wien) 154:17071710, 2012

19. Mario Zanaty NC, 2 Robert M. Starke,3 Pascal Jabbour,2 Katherine O. Ryken,1 Ketan R. Bulsara,4 and David Hasan1: Failure of the Pipeline Embolization Device in Posterior Communicating Artery Aneurysms Associated with a Fetal Posterior Cerebral Artery. Case Rep Vasc Med 2016:4691275, 2016

20. Pistocchi S, Blanc R, Bartolini B, Piotin M: Flow diverters at and beyond the level of the circle of willis for the treatment of intracranial aneurysms. Stroke 43:1032-1038, 2012

21. Puri AS, Massari F, Asai T, Marosfoi M, Kan P, Hou SY, et al: Safety, efficacy, and short-term follow-up of the use of Pipeline Embolization Device in small $(<2.5 \mathrm{~mm})$ cerebral vessels for aneurysm treatment: single institution experience. Neuroradiology 58:267-275, 2016

22. Safain MG, Roguski M, Heller RS, Malek AM: Flow Diverter Therapy With the Pipeline Embolization Device Is Associated With an Elevated Rate of Delayed Fluid-Attenuated Inversion Recovery Lesions. Stroke 47:789797, 2016
23. Tomasello A, Romero N, Aixut S, Miquel MA Macho JM, Castano C, et al: Endovascular treatment of intracraneal aneurysm with pipeline embolization device: experience in four centres in Barcelona. Neurol Res 38:381388, 2016

24. van Gijn J: Subarachnoid haemorrhage: diagnosis, causes and management. Brain 124:249-278, 2001

25. Yang W, Huang J: Treatment of middle cerebral artery (MCA) aneurysms: a review of the literature. Chinese Neurosurgical Journal 1, 2015

26. Zanaty M, Chalouhi N, Tjoumakaris SI, Gonzalez LF, Rosenwasser R, Jabbour P: Flow diversion for complex middle cerebral artery aneurysms. Neuroradiology 56:381-387, 2014

27. Zanaty M, Daou B, Chalouhi N, Starke RM, Samaniego E, Derdeyn C, et al: Same-Day Discharge Following Treatment with the Pipeline Embolization Device Using Monitored Anesthesia Care. World Neurosurg. 2016

28. Giacomini L, Piske LR, Baccin EC, Barroso M Joaquim AF, Tedeschi H, et al: Neurovacular reconstruction with flow diverter stents for the treatment of 87 intracranial aneurysms: Clinical results. Interv Neuroradiol 21:292299, 2015

29. Chalouhi N, Tjoumakaris S, Philips JL, Starke RM, Hasan D, Wu C, et al: A single pipeline embolization device is sufficient for treatment of intracranial aneurysms. Am J Neuroradiol 35:1562-6, 2014

30. Siddiqui A, Abla AA, Kan P, Dumont TM, Jahshan S, Britz G, Hopkins NL, et al: Panacea or problem: flow diverters in the treatment of symptomatic large or giant fusiform vertebrobasilar aneurysms. J Neurosurg 116:12581266, 2012

31. Shapiro M, Becske T, Nelson PK: Learning from failure: persistence of aneurysms following pipeline embolization J Neurosurg 126:578-585, 2017 